\section{Investigation of health status, treatment methods, and musculoskeletal injuries of the sportsmen according to branches}

\section{Sporcuların branşlara göre sağlık durumları tedavi yöntemleri ve kas iskelet sistemi yaralanmalarının incelenmes $^{1}$}

\author{
Yücel Ocak ${ }^{2}$ \\ Sebiha Gölünük Başpınar ${ }^{3}$ \\ Gülseren Bebek ${ }^{4}$
}

\begin{abstract}
Background and Aim: Sports injuries are the common name of all kinds of injuries generally occurring during sport activities. Besides, they are also stated as the case preventing participation in sport the day after the injury occurs. Injuries are the ones generally arising either due to a single internal or external major trauma (bone fracture, muscle tearing, tissue injuries, and so on) or recurrent microtraumas (apophysitis, stress fractures, tendonitis, and so on).

In this study, it was aimed to detect the health problems and types of injuries encountered by sportsmen continuing their sport life in different branches and to reveal the relationships of these health problems and types of injuries with sports branch, demographical features, and lifestyle.

Method: A total of 604 people including 332 males and 272 females between the ages of 17-26 and in six different branches participated in the study. The participants voluntarily attended the study. They signed a voluntary participation consent form. The
\end{abstract}

Özet

Giriş ve Amaç: Spor sakatlikları genel olarak sportif aktiviteler esnasinda meydana gelen her türlü hasarın ortak adıdır. Bunun yanı sıra sakatlığın oluştuğu günün ertesinde spora katılımı engelleyen durum olarak da ifade edilmektedir. Yaralanmalar genel olarak ya içsel ya da dişsal kaynaklı tek bir büyük travmaya bağlı (kemik kırıkları kas yırtılmaları ve bağ yaralanmaları vb.) Ya da tekrarlayan mikro travmalara bağlı gelişen (apofizitis, stres kırıkları, tendonitis vb.) yaralanmalardır.

Bu çalışmada; farklı branşlarda sportif yaşantısını devam ettiren sporcuların karşılaştıkları sağlık sorunları ve sakatlık türlerinin belirlenmesi, bu sağlık sorunları ve sakatlık türlerinin spor branşılla, demografik özellikleriyle ve yaşam tarzıyla olan ilişkilerinin belirlenmesi amaçlanmıştır.

Yöntem: Çalışmaya 17-26 yaş aralığında, 6 farklı branşta, 332 erkek, 272 kadın toplamda 604 kişi katılmıştır. Katılımcılar araştırmaya gönüllü olarak katılmışlardır. Katılımcılara gönüllü katılım onan formu imzalatılmıştır. Çalışmada anket yöntemi

\footnotetext{
1 Bu Çalş̧ma "Branşlara Göre Kas İskelet Sistemi Yaralanmaları" ismiyle 28 Haziran 2018 de Venedik İtalyada "International Congress on Political, Economic and Social Studies (ICPESS)" isimli kongrede sözel sunum olarak sunulmuştur.

2 Prof. Dr., Afyon Kocatepe Üniversitesi, Beden Eğitimi ve Spor Yüksekokulu, yocak@aku.edu.tr (iD) Orcid ID: https://orcid.org/0000-0002-2037-6131

${ }^{3}$ Dr. Öğr. Üyesi, Afyon Kocatepe Üniversitesi, Beden Eğitimi ve Spor Yüksekokulu, sgolunuk@aku.edu.tr (D) Orcid ID: https://orcid.org/0000-0002-6342-2265

4Afyon Kocatepe Üniversitesi, Sağlık Bilimleri Enstitüsü, Beden Eğitimi ve Spor Anabilim Dalı, bebekgulseren@yahoo.com (iD) Orcid ID: https://orcid.org/0000-0002-9816-9968
} 
Göktepe, M. M., \& Günay, M. (2019). Kadın futbolculara uygulanan proprioseptif egzersiz programının, denge, proprioseptif duyu ve fonksiyonel performans üzerine etkisi. Journal of Human Sciences, 16(4), 1145-1155. doi:10.14687/ihs.v16i4.5863

survey method was used in the study. A "Sportsman Health Information Form" that was formed by the Sportsman Health and Research Centre was arranged and given its final form by the researcher, and it was conducted to the participants. The obtained data were analysed with the SPSS package programme. First, normal distribution of the data was checked, and they were analysed with nonparametric tests as they did not show a normal distribution. In the analysis, percentages and frequencies were controlled and Kruskal Wallis Analyses were also carried out for the correlation of the variables. It was evaluated at the level of 0,05 at the significant point.

Results: It was seen that the participants had the problems such as vision disorders, pitting, loss of feeling, breathing disorders, chest pain, and having frequent cramps, and this situation varied across branches. It was concluded that $49 \%$ of the participants were exposed to injuries of muscle, bone, and tendon.

Keywords: Sports injuries, musculoskeletal system, sports branch, health.

Extended English summary is at the end of this document) kullanılmıştır. Sporcu Sağllğı ve Araştırma Merkezi (SESAM) tarafindan oluşturulan, "Sporcu Sağlığ1 Bilgi Formu" araştırmacı tarafından düzenlenerek son sekli verilmiş ve katılımcılara uygulanmıştır. Elde edilen veriler SPSS paket programı ile analiz edilmiştir. Öncelikle verilerin normal dağılımına bakılmış ve normal dağılım göstermediği için nonparametrik testlerle analiz edilmiştir. Değerlendirmelerde yüzde ve frekanslara bakılmış, değişkenler arasındaki ilişkilendirmelere de Kuruskal-Wallis analizleri uygulanmıștır. Anlamlılık noktasında 0,05 seviyesinde değerlendirilmiştir.

Sonuç: Katılımcıların görme, uyuşma ve his kayb1, nefes alma, göğüs ağrisı ve sıksık kramp girme gibi sağlık sorunları yaşadı̆̆1 ve bu durumun branşlar arasında farkliliklar gösterdiği, yine \% 49'nun kas kemik ve tendon yaralanmalarına maruz kaldıkları görülmüştür.

Anahtar Kelimeler: Spor sakatlı̆̆1, kas iskelet sistemi, spor branşı, sağlık.

\section{Giriş}

Spor yaralanmaları, sportif aktiviteler sırasın da oluşan her türlü sakatlık yada yaralanmaya verilen isimdir (Kılıç B. ve ark.). Spor yaşam kalitesi üzerine önemli etkilere sahiptir. Özellikle genç, çocuk, yaşlı ayırt etmeksizin tüm yaş gruplarına spor alışkanlığının kazandırılması ve yaşam boyunca sürdürülmesi önemlidir. Spor ve Fiziksel Aktivite, kognitif fonksiyon, yaşam kalitesi ve fiziksel sağlık konusun da önemli etkilere sahiptir. Spor branşlarında yeterli önlemler alınmadığında, sporun gerektirdiği yüksek düzeydeki fiziksel performans, birçok iç ve dış faktöre bağlı olarak spor sakatlığına neden olmaktadır (Kisser \& Bauer, 2012). Spor yaralanması 1-7 gün sürebilen hafif yaralanmalar,8-21 gün süren orta düzey yaralanmalar ve 21 günden fazla sürebilen ciddi yaralanmalar olarak sinıflandirılabilir (Emrah A. ve ark. 2017).

Argut ve Çelik, sportif tedavi gerektiren sakatlıkların \%14'ünün sporla ilişkili olduğu ifade etmişlerdir (Argut, S. K., \& Çelik, D. 2018). Yapılan bir başka araştırmada olimpiyat oyunlarında yaralanma oranlarının yaklaşık \%67 seviyesinde olduğu bildirilmiştir (Palmer-Green \& Elliott, 2015). Bu yaralanmalar veya sakatliklar sporcunun spor hayatına devam etmesini engellemekte ya da eski performansına ulaşamamasına neden olmaktadır. Rekabet ortamının arttı̆̆ı, birincilerin saliselerle ya da çok az puan farklarıyla belirlendiği bir ortamda bulunmaktayı. Bu zor şartlar birçok sporcunun sakatlanmasına ve sporu birakmasina sebebiyet vermektedir. Cumps ve arkadaşları, spor sakatlıklarının sporcunun sadece spor kariyerini tehlikeye atmayıp, aynı zamanda sporcunun fiziksel ve psikolojik sağlığını olumsuz yönde etkilediğini ifade etmişlerdir. Ayrıca bu durumun hem sporcu, hem kulüp hem de ülke için ekonomik yük oluşturduğunu belirtmişlerdir (Cumps, E. ve ark. 2003).

Birçok sporcu, kazanmak, rakibine üstünlük sağlamak, ülkesini en iyi noktada temsil etmek, maddi ve manevi kazanç elde etmek, toplumsal statü kazanmak ve en iyi olduğunu ispat etmek gibi birçok faktöre bağlı olarak, daha fazla risk almakta, gerekli koruyucu önlemleri almamakta ve 
Göktepe, M. M., \& Günay, M. (2019). Kadın futbolculara uygulanan proprioseptif egzersiz programının, denge, proprioseptif duyu ve fonksiyonel performans üzerine etkisi. Journal of Human Sciences, 16(4), 1145-1155. doi:10.14687/jhs.v16i4.5863

tedavi süreçlerini tamamlamadan müsabakalara devam etmektedirler. Bu durumda da sakatllk kaçınılmaz olmaktadır.

Bu çalışmada; farklı branşlar da sportif yaşantısını devam ettiren sporcuların karşılaştıkları sağlık sorunları ve sakatlık türlerinin belirlenmesi, bu sağlık sorunları ve sakatlık türlerinin spor branşıyla ve demografik özellikleriyle olan ilişkilerinin belirlenmesi amaçlanmıştır.

\section{Yöntem}

Çalışmaya Üniversitelerde eğitim ve öğretimlerine devam eden 17-26 yaş aralığında, Atletizm, Tenis, Güreş, Badminton, Futbol, Basketbol ve Voleybol branşlarından 332 erkek, 272 kadın toplamda 604 kişi katılmıştır. Katılımcılar araştırmaya gönüllü olarak katılmışlardır. Katılımcilara gönüllü katılım onan formu imzalatılmıştır.

Çalışmada anket yöntemi kullanılmıştır. Sporcu Sağlığı ve Araştırma Merkezi (SESAM) tarafından oluşturulan, "Sporcu Sağlı̆̆1 Bilgi Formu" araştırmacı tarafindan düzenlenerek son şekli verilmiş ve katılımcılara uygulanmıştır. Ankette kişisel bilgiler ve karşılaşılan sağlık sorunlarının belirlenmesine yönelik sorular bulunmaktadır.

Elde edilen veriler SPSS paket programı ile analiz edilmiştir. Öncelikle verilerin normal dağılımına bakılmış ve normal dağglım göstermediği için nonparametrik testlerle analiz edilmiştir. Değerlendirmelerde yüzde ve frekanslara bakılmış, değişkenler arasındaki ilişkilendirmelere de Kuruskal-Wallis analizleri uygulanmıştır. Anlamllık noktasında 0,05 seviyesinde değerlendirilmiştir.

\section{Bulgular}

Tablo 1 ve 2 de katılımcıların demografik özellikleri ve değişkenleri görülmektedir.

Tablo 1: Katılımciların Demografik Özellikleri

\begin{tabular}{|c|c|c|c|}
\hline PARAI & RELER & $\mathbf{N}$ & $\%$ \\
\hline \multirow{6}{*}{ Yaş } & $17-18$ yaș & 58 & 9,6 \\
\hline & $19-20$ yaș & 274 & 45,4 \\
\hline & $21-22$ yas & 182 & 30,1 \\
\hline & $23-24$ yaș & 49 & 8,1 \\
\hline & $25-26$ yass & $41 \ldots$ & 6.8 \\
\hline & Total & 604 & 100,0 \\
\hline \multirow{8}{*}{ Branş } & Atletizm & 74 & 12,3 \\
\hline & Tenis & 47 & 7,8 \\
\hline & Güres & 89 & 14,7 \\
\hline & Badminton & 28 & 4,6 \\
\hline & Futbol & 196 & 32,5 \\
\hline & Basketbol & 89 & 14,7 \\
\hline & Voleybol & 81 & 13,4 \\
\hline & Total & 604 & 100,0 \\
\hline \multirow{3}{*}{ Cinsiyet } & Erkek & 332 & 55,0 \\
\hline & Kadin & 272 & 45,0 \\
\hline & Total & 604 & 100,0 \\
\hline
\end{tabular}


Göktepe, M. M., \& Günay, M. (2019). Kadın futbolculara uygulanan proprioseptif egzersiz programının, denge, proprioseptif duyu ve fonksiyonel performans üzerine etkisi. Journal of Human Sciences, 16(4), 1145-1155. doi:10.14687/jhs.v16i4.5863

Tablo 2: Katılımcıların Demografik Değişkenleri

\begin{tabular}{|c|c|c|c|}
\hline Parametreler & Fakülte & $\mathbf{n}$ & $\%$ \\
\hline \multirow{2}{*}{ Öğrenim Durumu } & BESYO & 383 & 63,4 \\
\hline & Diğer Bölümler & 221 & 36,6 \\
\hline \multirow{8}{*}{$\begin{array}{c}\text { Spora } \\
\text { Başlama } \\
\text { Yaşı }\end{array}$} & $5-6$ & 7 & 1,2 \\
\hline & $7-8$ & 92 & 15,2 \\
\hline & $9-10$ & 157 & 26,0 \\
\hline & $11-12$ & 141 & 23,3 \\
\hline & $13-14$ & 85 & 14,1 \\
\hline & $15-16$ & 55 & 91 \\
\hline & $17-18$ & 35 & 58 \\
\hline & 19 ve üzeri & 32 & 5.3 \\
\hline \multirow{5}{*}{$\begin{array}{c}\text { Haftalik Antrenman } \\
\text { Sayıs } 1\end{array}$} & $1-2$ saat & 16 & 2,6 \\
\hline & 3-4 saat & 94 & 15,6 \\
\hline & 5-6 saat & 200 & 33,1 \\
\hline & 7-8 saat & 131 & 21,7 \\
\hline & $9-10$ saat & 163 & 27.0 \\
\hline \multirow{6}{*}{$\begin{array}{l}\text { İlk Ağırlık } \\
\text { Çalışması } \\
\text { Yaptığ1 Yaş }\end{array}$} & $10-11$ yas & 8 & 1,3 \\
\hline & 12-13 yas & 91. & 15,1 \\
\hline & $14-15$ vas & 200 & 33,1 \\
\hline & 16-17..vas & 178 & 29,5 \\
\hline & 18-19yas & 85 & 14,1 \\
\hline & 20 ve üzeri & 42 & 7,0 \\
\hline
\end{tabular}

Tablo 3: Katılımcıların Sağlık Problemleri Dağılımı ve İlişkileri

\begin{tabular}{|c|c|c|c|c|c|c|}
\hline Sağl1k Problemleri & Branş & $\mathbf{n}$ & Ort. & Std. Sap. & Sira Ort. & $\mathrm{p}$ \\
\hline \multirow{7}{*}{ Görme Sorunu } & Atletizm & 74 & 1,69 & ,466 & 282,14 & \multirow{7}{*}{$0,02^{*}$} \\
\hline & Tenis & 47 & 1,53 &, 504 & 234,64 & \\
\hline & Güreş & 89 & 1,74 & 440 & 297,96 & \\
\hline & Badminton & 28 & 1,68 & 476 & 278,93 & \\
\hline & Futbol & 196 & 1,81 & 396 & 317,45 & \\
\hline & Basketbol & 89 & 1,82 & ,386 & 321,71 & \\
\hline & Voleybol & 81 & 1,80 & ,401 & 316,35 & \\
\hline \multirow{7}{*}{ İşitme Problemi } & Atletizm & 74 & 1,95 & 228 & 290,18 & \multirow{7}{*}{$0,01 * *$} \\
\hline & Tenis & 47 & 2,00 &, 000 & 306,50 & \\
\hline & Güreş & 89 & 1,96 & 208 & 292,93 & \\
\hline & Badminton & 28 & 2,00 & 000 & 306,50 & \\
\hline & Futbol & 196 & 2,00 &, 000 & 306,50 & \\
\hline & Basketbol & 89 & 2,00 & ,000 & 306,50 & \\
\hline & Voleybol & 81 & 2,00 & ,000 & 306,50 & \\
\hline \multirow{7}{*}{ Sik Sik Kramp Girmesi } & Atletizm & 74 & 1,58 & ,497 & 248,99 & \multirow{7}{*}{$0,00^{* *}$} \\
\hline & Tenis & 47 & 1,66 & ,497 & 272,69 & \\
\hline & Güreş & 89 & 1,57 & ,497 & 246,56 & \\
\hline & Badminton & 28 & 1,46 & ,508 & 213,71 & \\
\hline & Futbol & 196 & 1,97 & ,173 & 366,26 & \\
\hline & Basketbol & 89 & 1,73 & ,446 & 294,06 & \\
\hline & Voleybol & 81 & 1,80 & , 401 & 315,85 & \\
\hline
\end{tabular}


Göktepe, M. M., \& Günay, M. (2019). Kadın futbolculara uygulanan proprioseptif egzersiz programının, denge, proprioseptif duyu ve fonksiyonel performans üzerine etkisi. Journal of Human Sciences, 16(4), 1145-1155. doi:10.14687/jhs.v16i4.5863

\begin{tabular}{|c|c|c|c|c|c|c|}
\hline \multirow{7}{*}{ Nefes Alma Sorunu } & Atletizm & 74 & 1,43 & ,503 & 200,92 & \multirow{7}{*}{$0,00 * *$} \\
\hline & Tenis & 47 & 2,00 & 000 & 356,00 & \\
\hline & Güreş & 89 & 1,79 & ,412 & 291,53 & \\
\hline & Badminton & 28 & 2,00 & 000 & 356,00 & \\
\hline & Futbol & 196 & 1,86 & ,346 & 314,40 & \\
\hline & Basketbol & 89 & 1,88 & ,331 & 318,67 & \\
\hline & Voleybol & 81 & 1,80 & ,401 & 311,26 & \\
\hline \multirow{7}{*}{ Uyuşma ve His Kaybı } & Atletizm & 74 & 1,80 & ,405 & 286,78 & \multirow{7}{*}{$0,000^{* *}$} \\
\hline & Tenis & 47 & 1,70 & 462 & 251,62 & \\
\hline & Güreş & 89 & 1,88 & ,331 & 310,67 & \\
\hline & Badminton & 28 & 1,86 & ,356 & 304,86 & \\
\hline & Futbol & 196 & 1,96 & ,198 & 335,67 & \\
\hline & Basketbol & 89 & 1,88 & ,331 & 310,67 & \\
\hline & Voleybol & 81 & 1,67 & ,474 & 247,33 & \\
\hline \multirow{7}{*}{ Göğüs Ağr1s1 } & Atletizm & 74 & 1,73 & ,447 & 259,38 & \multirow{7}{*}{$0,000^{* *}$} \\
\hline & Tenis & 47 & 1,85 &, 360 & 296,02 & \\
\hline & Güreş & 89 & 1,81 & ,395 & 283,31 & \\
\hline & Badminton & 28 & 1,86 & ,356 & 297,86 & \\
\hline & Futbol & 196 & 1,96 & ,198 & 328,67 & \\
\hline & Basketbol & 89 & 1,84 & ,366 & 293,49 & \\
\hline & Voleybol & 81 & 1,91 & 283 & 314,90 & \\
\hline
\end{tabular}

\section{$* \mathrm{P}<0,05, \quad * * \mathrm{p}<0,01$}

Tablo 3 de katılımcıların branşlara göre sağlık problemlerinin dağılımı ve ilişkileri görülmektedir. Branşlar arasında sağlık problemlerinin dağılımında farklılıklar görülmüştür. $\mathrm{Bu}$ farklılıklarda istatistiki olarak anlamlıdır.

\section{Tablo 4: Katılımcıların Spor Sakatlıkları ve Tedavi Durumları}

\begin{tabular}{|c|c|c|c|}
\hline Parametreler & $\mathrm{E} / \mathrm{H}$ & $\mathbf{n}$ & $\%$ \\
\hline \multirow{2}{*}{ Hafıza ve Dikkat Probleminiz Var mı? } & Evet & 71 & 11,8 \\
\hline & Haylr & 533 & 88,2 \\
\hline \multirow{2}{*}{ Kas Kemik ve Tendon Yaralanması Geçirdiniz mi? } & Evet & 296 & 49,0 \\
\hline & Hayır & 308 & 51,0 \\
\hline \multirow{2}{*}{ Spor Sakatlığından Dolayı Bir Ameliyat Önerildi mi? } & Evet & 50 & 8,3 \\
\hline & Hayır & 554 & 91,7 \\
\hline \multirow{2}{*}{ Spor Sakatlığından Dolayı Bir Ameliyat Oldunuz mu? } & Evet & 19 & 3,1 \\
\hline & Hayır & 585 & 96,9 \\
\hline \multirow{2}{*}{ Vücudunuza Protez Takıldı mı? } & Evet & 6 & 1,0 \\
\hline & Haylr & 598 & 99,0 \\
\hline
\end{tabular}

Tablo 4 de katılımcıların spor sakatlıkları ve tedavi durumlarının oranları görülmektedir. Katılımcıların neredeyse yarısı kas kemik ve tendon yaralanması geçirdiklerini ifade etmektedirler. 
Göktepe, M. M., \& Günay, M. (2019). Kadın futbolculara uygulanan proprioseptif egzersiz programının, denge, proprioseptif duyu ve fonksiyonel performans üzerine etkisi. Journal of Human Sciences, 16(4), 1145-1155. doi:10.14687/jhs.v16i4.5863

Tablo 5: Katılımcıların Spor Sakatlıkları ve Tedavi Durumları İlişkisi

\begin{tabular}{|c|c|c|c|c|c|c|}
\hline Spor sakatlıkları & Branş & $\mathbf{n}$ & Ort. & Std. Sap. & Sira Ort. & $\mathrm{p}$ \\
\hline \multirow{7}{*}{$\begin{array}{l}\text { Kas Kemik ve Tendon } \\
\text { Yaralanması Geçirdiniz mi? }\end{array}$} & Atletizm & 74 & 1,42 & 497 & 275,01 & \multirow{7}{*}{$0,000^{* *}$} \\
\hline & Tenis & 47 & 1,38 & 491 & 264,16 & \\
\hline & Güreș & 89 & 1,21 & , 412 & 212,97 & \\
\hline & Badminton & 28 & 1,50 & 509 & 299,50 & \\
\hline & Futbol & 196 & 1,68 & ,468 & 353,43 & \\
\hline & Basketbol & 89 & 1,66 & 475 & 348,70 & \\
\hline & Voleybol & 81 & 1,42 & 497 & 275,27 & \\
\hline \multirow{7}{*}{$\begin{array}{l}\text { Spor Sakatlığından Dolayı Bir } \\
\text { Ameliyat Önerildi mi? }\end{array}$} & Atletizm & 74 & 2,00 & 000 & 312.00 & \multirow{7}{*}{$0,000 * *$} \\
\hline & Tenis & 47 & 1,91 & 282 & 312.00 & \\
\hline & Güreș & 89 & 1,83 & 376 & 288.25 & \\
\hline & Badminton & 28 & 2,00 &, 000 & 312.00 & \\
\hline & Futbol & 196 & 1,88 & 329 & 293.51 & \\
\hline & Basketbol & 89 & 2,00 & 000 & 312.00 & \\
\hline & Voleybol & 81 & 1,91 & 283 & 312.00 & \\
\hline \multirow{7}{*}{$\begin{array}{l}\text { Spor Sakatlığından Dolayı Bir } \\
\text { Ameliyat Önerildi mi? }\end{array}$} & Atletizm & 74 & 2,00 &, 000 & 327,50 & \multirow{7}{*}{$0,001 * *$} \\
\hline & Tenis & 47 & 2,00 & 000 & 301,80 & \\
\hline & Güreș & 89 & 1,92 & 271 & 276,60 & \\
\hline & Badminton & 28 & 2,00 & 000 & 327,50 & \\
\hline & Futbol & 196 & 1,94 & 240 & 290,52 & \\
\hline & Basketbol & 89 & 2,00 & 000 & 327,50 & \\
\hline & Voleybol & 81 & 2,00 & 000 & 301,40 & \\
\hline \multirow{7}{*}{ Şu an Tedavi Altındamısınız } & Atletizm & 74 & 1,64 & 485 & 257,31 & \multirow{7}{*}{$0,000 * *$} \\
\hline & Tenis & 47 & 1,62 & 491 & 251,84 & \\
\hline & Güreș & 89 & 1,83 & 376 & 316,60 & \\
\hline & Badminton & 28 & 1,43 & 504 & 194,93 & \\
\hline & Futbol & 196 & 1,87 & ,334 & 328,98 & \\
\hline & Basketbol & 89 & 1,89 & 318 & 333,57 & \\
\hline & Voleybol & 81 & 1,77 & 426 & 296,66 & \\
\hline \multirow{7}{*}{$\begin{array}{l}\text { Vücudunuza } \\
\text { mi? }\end{array}$} & Atletizm & 74 & 2,00 &, 000 & 305,50 & \multirow{7}{*}{0,050} \\
\hline & Tenis & 47 & 2,00 &, 000 & 305,50 & \\
\hline & Güres & 89 & 2,00 & 000 & 305,50 & \\
\hline & Badminton & 28 & 2,00 &, 000 & 305,50 & \\
\hline & Futbol & 196 & 1,97 & 173 & 296,26 & \\
\hline & Basketbol & 89 & 2,00 & 000 & 305,50 & \\
\hline & Voleybol & 81 & 2,00 &, 000 & 305,50 & \\
\hline
\end{tabular}

$* \mathrm{P}<0,05, \quad * * \mathrm{p}<0,01$

Tablo 5 de katılımcıların branşlara göre spor sakatlıkları ve tedavi durumlarının dağılımı ve ilişkileri görülmektedir. Branşlar arasında spor sakatlıkları ve tedavi durumlarının dağılımında farklılıklar görülmüştür. Bu farklılıklarda istatistiki olarak da anlamlı farklılığı ortaya koymaktadır.

\section{Tartışma}

Farklı branşlardaki sporcuların sağlık durumları, spor sakatlıkları özelliklede kas iskelet sistemi yaralanmaları ve branşlar arasındaki farklılıklarının belirlenmesine yönelik bu çalışmaya 604 sporcu katılmıştır. 17 -26 yaş aralığında olan bu katılımcıların 74 tanesi Atletizm, 47 tanesi tenis, 89 tanesi güreş, 28 tanesi badminton, 196 tanesi futbol, 89 tanesi basketbol ve 81 tanesi de voleybol branşında olan sporculardı. Ayrıca kattlımcıların 332 tanesi erkek, 272 tanesi de bayan sporculardan oluşmuş̧tur.

Katılımcıların hepsi üniversite öğrencisidir. Bölüm dağılımlarına bakıldığında 383 tanesi Spor Bilimlerinde öğrenim görürken, 221 tanesi de farklı bölümlerde öğrenimlerine devam etmektedirler. Katılımcıların 157 tanesi \%26 oranla 9-10 yaşlarında spora başladıklarını ifade etmişlerdir. Haftada 5-6 antrenman yapan 200 katılımc1, \% 33 oranı oluştururken, haftada 9-10 antrenman yapan 
Göktepe, M. M., \& Günay, M. (2019). Kadın futbolculara uygulanan proprioseptif egzersiz programının, denge, proprioseptif duyu ve fonksiyonel performans üzerine etkisi. Journal of Human Sciences, 16(4), 1145-1155. doi:10.14687/jhs.v16i4.5863

katılımcıların sayısı 163 kişidir. Bu sayıda \%27’lik bir oranı oluşturmaktadır. İlk ağırlık çalışmasına başladıkları yaş sorulduğunda, 10-13 yaş aralı̆̆ında ağırlık çalışmasına başlayan sporcu sayısı 99 iken, bu rakam \% 16,4 bir orana karşılık gelmekteydi. Bu rakamlara bakıldığında çocuklarımızı eğiten antrenörlerin yetersizliği gözler önüne serilmektedir. Yine 14-15 yaş aralı̆̆ında ağırlık çalışmasına başladım diyen katılımcıların sayısı 200 iken bu rakamda \% 33 oranına karşılık gelmekteydi. İkinci ergenlik dönemine karşılık gelen bu yaş aralığı kabül edilebilir durumdur.

Katılımcıların sağlık sorunlarının dağılımı ve branşlar arasındaki ilişkilere bakıldığında, Basketbol, Futbol ve Voleybol branşlarındaki sporcuların; sırasıly tenis, badminton, atletizm ve güreş branşındaki sporculara oranla daha az görme sorunu yaşadıkları gözlenmiştir. Bu farklılıklar istatistiki olarak da anlamlılığ ifade etmektedir. Burada dikkati çeken diğer husus ise tenisçilerin diğer branşlara oranla en fazla görme sorunu yaşadıklarıdır. Bu durum teniscilerin odaklanmayla ilgili daha özel bir beceriye sahip olma zorunlulukları vardır. Çünkü bir tenis müsabakasın topun hızı $250 \mathrm{~km}$ lere ulaşabilmektedir(Yeşilpınar S. 2013). Bu çok yüksek hız görmeyle ilgili sorunlar yaşatabilmektedir.

Branşların işitme problemleri incelendiğinde, Çok düşük oranda da olsa işitme sorunu yaşıyoruz diyen branşlar Atletizm ve Güreş olduğu görülmüştür. Diğer branşların ise işitme sorunu yaşamadıklarını belirtmişlerdir. Branşlar arasındaki bu farkllıklar istatistiki olarak da anlamlı bulunmuştur $\mathrm{p}<0,01$. Dört branşın işitme sorunuyla ilgili cevapların aynı olması, özellikle takım sporlarının, işitme sorunlarının benzer olması ve sadece iki bireysel branşın işitme sorununu daha düşük oranda yaşaması, takım ve bireysel branşlarda bir farklılığın oluştuğunun göstergesi gibi düşünülebilir.

Kramp yaşanmasıyla ilgili sorumuza da en yüksek oranda badmintoncuların sık sık krampla karşılaştıkları görülmüşür. Daha sonra güreşçiler, atletizmciler ve tenisçiler yükssek oranda kramp yaşadıklarını ifade etmişlerdir. Futbolcuların, voleybolcuların ve basketbolcuların daha düşük oranda kramp sorunu yaşadıkları gözlenmiştir. Branşlar arasındaki bu farklılıklar istatistiki olarak da anlamlık ifade etmiştir $\mathrm{p}<0,01$. Bireysel sporcularda görülen daha fazla kramp yaşanması, bu branşlarda fiziksel yüklenmelerin interval ortamda çok yoğun ve maksimal şiddetlerde yapılması ve özellikle de tenis ve badminton gibi müsabaka zeminlerinin sertliği ve sürelerinin çok uzun olmasıyla da açıklanabilir. Ayrıca Güreşçilerdeki kramp sorununun yüksek oranda yaşanması, mücadele sporları içerisinde rakip temasıyla çok yüksek bir zorlukta yapılan bir branş olması gerçeğiyle açıklanabilir. Kurt ve arkadaşları yaptıkları bir araştırmada sıklet sporcularında \% 20 oranında kramp görüldügünü ifade etmişlerdir (Kurt ve ark. 2006).

Araştırma bulgularında en fazla nefes alma sorunu yaşayan branşın atletizm olduğu görülmektedir. Nefes alma sorunu hiç yaşamayan branşlar ise tenis ve badmintondur. Diğer branşlar ise çok düşük oranda nefes alma sorunu yaşadıklarını ifade etmişlerdir. Branşlar arasındaki bu farklılıklar istatistiki olarak da anlamlıdır $\mathrm{p}<0,01$. Atletizm branşında diğer branşlara oranla daha fazla nefes alma sorunu yaşanması branşın bir özelliği olarak görülebilir. Atletizmde özelikle yüksek bir anaerobik dayanıklılık gerektiren koşularda oksijen borçlanmasının çok yüksek oranda oluşması, bu farklılı̆g oluşturabilir.

Sporculara uyuşma ve his kaybı yaşanmasıyla ilgili sorulan soruya verilen cevaplarda, sırasıyla en yüksek oranda his kaybını voleybolcular ve tenisciler yaşadıklarını ifade etmişlerdir. Diğer branşlarda ise uyuşma ve his kaybı yaşama oranlarının oldukça az olduğu görülmüştür. Branşlar arasındaki bu farklilıklar istatistiki olarak da anlamlılığ ifade etmektedir $\mathrm{p}<0,00$. Bu durum ve farklılıklar branşların spesifik yapılarıyla açıklanabilir. Özellikle teniscilerin ve voleybolcuların branşa özgü mesleki sakatlıkları olarak da görülen tenisçi dirseği "lateral epikondilit" ve Omuzda Tendon Sıkışması "Omuz Impingement sendromu" sakatlığına maruz kaldıkları görülmektedir (Kolukısa ve ark. 2018; Belhan, O. Karakurt, L. 2008; Ölmez, N. Memiş, A. 2010; Sims, S.E. ve ark. 2014; Singh, P. ve ark. 2019; Rosa, D. P. ve ark. 2019; Özcan ve ark. 1990). 
Göktepe, M. M., \& Günay, M. (2019). Kadın futbolculara uygulanan proprioseptif egzersiz programının, denge, proprioseptif duyu ve fonksiyonel performans üzerine etkisi. Journal of Human Sciences, 16(4), 1145-1155. doi:10.14687/jhs.v16i4.5863

Katılımcılanın göğüs ağnısı yaşamalarıyla ilgili sorulara verdikleri cevapta, yine benzer şekilde nefes alma sorununda olduğu gibi en yüksek oranda göğüs ağrısını Atletizmciler yaşamışlardır. Diğer branşlarda ise göğüs ağrısı yaşama oranlarının oldukça az oranlarda olduğu görülmüştür. Branşlar arasındaki bu farklılıklar istatistiki olarak da anlamlıdır $\mathrm{p}<0,00$. Bu durum atletizmin bazı branşlarının yapısal özelliği ile açıklanabilir. Yünceviz ve arkadaşları yaptıkları bir araştırmada, Avrupa, Dünya ve Olimpiyat şampiyonalannda ilk üç dereceyi paylaşmış Türk güreşçilerinde oluşan spor sakatlıklarının vücut bölgelerine göre dağılımı incelenmişlerdir. Sakatlanma riski açısından göğüs bölgesi sakatlıklarının büyüklerde, gençlerden daha fazla olduğu, sakatlıklarının GrekoRomen güreşte, serbest güreşten anlamlı bir şekilde daha fazla görüldüğü belirtmişlerdir (Yünceviz ve ark. 1997).

Yapılan bu araştırmada, katılımcılara Hafiza ve Dikkat Probleminiz Var mı? Şeklindeki soru sorulmuş ve katılımciların \% 88’i hayır şeklinde cevap vermişlerdir. Bu cevaplarda beklenen bir sonucun göstergesidir. Hangi branş olursa olsun performans sporcusunda yüksek bir ilgi, dikkat ve konsantrasyona ihtiyaç duyulmaktadır.

Çalışma sonuçlarında dikkati çeken önemli bulgulardan bir tanesi de katılımcıların \% 49’u Kas, kemik ve tendon Yaralanması geçirdiklerini ifade etmeleridir. Bir başka ifadeyle de araştırmacıların yarısı spor sakatlığı yaşamışlardır.

Katılımcılara spor sakatlığından dolayı bir ameliyat önerildi mi sorusuna evet diyenlerin oranı $\%$ 8,3 iken, spor sakatlığından dolayı bir ameliyat oldum diyenlerin oranı da \% 3,1 dir. Vücudunuza bir protez takıldı mı sorusuna evet cevabı veren 6 kişi bulunmaktaydı, bu sayının yüzdelik karşılığ da \% 1 dir. Görüldügü gibi sakatlıklar sonrası ameliyat gerektiren vakaların oranı ve ameliyat olan sporcuların sayısı oldukça azdır. Bu durum genellikle operasyon gerektirmeden sakatlıkların tedavi olduğu sonucunu çıkarmaktadır.

Spor sakatlıklarının branşlarla ilişkisine bakıldığında en fazla güreşçilerin ve tenisçilerin kas kemik ve tendon yaralanmasına maruz kaldıklanı, en düşük oranda ise futbolcuların kas kemik ve tendon yaralanmalarına maruz kaldığ1 görülmüştür. Branşlar arasındaki bu farklılıklar istatistiki olarak da anlamlllığı ifade etmektedir $\mathrm{p}<0,00$. Burada dikkati çeken unsur genel beklentinin dişında futbolcularda kas kemik ve tendon yaralanmalarının düşük çıkmasıdır. Güreşçilerde ise bu oranın yüksek çıkması branşa özgü bir özellik olarak görülebilir. Güreş rakip temasının en yüksek şiddette olduğu bir spor branşlarında bir tanesi olduğu için kas kemik ve tendon yaralanmaları daha yüksek oranda görülmüştür.

Özgür ve arkadaşları yaptıkları araştırmada voleybol ve futbolcularda ki sakatlıkları araştırmışlar, çalışmaya katılan 105 sporcudan 52'si (49,5\%) daha önce spor yaralanması geçirdiğini, 53 ü $(50,5 \%)$ ise daha önce yaralanma geçirmediğini belirtmiştir. Sakatliğın en s1k olarak alt eksremitede $(\% 88,5)$ ve yine en s1k olarak burkulma $(38,5 \%)$ şeklinde ortaya çıktı̆̆1 tespit etmişlerdir (Özgür ve ark 2016). Kolukısa ve arkadaşları 67 güreşçiyle yaptıkları bir çalışmada güreşçilerin \%097 sinin spor sakatlı̆̆ına mağruz kaldıklarını belirtmişlerdir (Kolukısa ve ark. 2018). Atay ve arkadaşları, güreşçilerde meydana gelen spor sakatlıklarının bölgelerini tespit etmek amacıyla 143 güreşçide yaptıkları araştırmada güreşçilerde en fazla sakatlığın görüldüğü bölgelerin \% $\% 3,4$ oranla diz, \%33,6 ayak-ayak bileği ve \%32,6 oranla omuz bölgelerinin olduğunu ifade etmişlerdir (Atay ve ark 2017). Yıldız ve arkadaşları amatör futbolcuların yetersiz antrenman, yetersiz 1sınma ve saha zemini gibi nedenlerden dolayı özellikle alt ekstremitelerde sıklıkla sakatlanmalara maruz kaldıkları tespit etmişlerdir (Yıldız M. 2010). Yıldız, yaptığı bir başka araştırmada, Foam Roller cihazı kullanılarak yapılan Miyofasyal gevşetme yönteminin, esnekliği artırdı̆̆ ve bu artışın futbolcularda kassal sakatlanma riskinide azaltabileceğini ifade etmisstir. Ögün ve ocak üst düzey basketbolcularla yaptıkları bir çalısmada, basketbolcuların büyük bir bölümünün sakatlanmaya maruz kaldıklarını ifade etmişlerdir. Ayrıca sakatlanma nedenlerinin oynama süreleri, oynanan zeminle ilişkili olduğunu belirtmişlerdir (Öğün E. 2018).

Literatür verilerinde görüldüğü gibi spor sakatlıkları oldukça yoğun yaşanmaktadır. Spor sakatlıkları, türleri ve sakatlıkların önlenmesine yönelik çok sayıda araştırmaya rastlanılmaktadır. 
Göktepe, M. M., \& Günay, M. (2019). Kadın futbolculara uygulanan proprioseptif egzersiz programının, denge, proprioseptif duyu ve fonksiyonel performans üzerine etkisi. Journal of Human Sciences, 16(4), 1145-1155. doi:10.14687/jhs.v16i4.5863

Katılımcılara spor sakatlığından dolayı bir ameliyat önerildi mi sorusuna en yüksek oranlarda güreşçiler evet demişlerdir. Atletizm, badminton ve basketbolcular hayır diye cevap vermişlerdir. Branşlar arasındaki bu farklliklar istatistiki olarak da anlamlilı̆̆ ifade etmektedir $\mathrm{p}<0,01$.Benzer şekilde spor sakatlığından dolayı bir ameliyat oldunuz mu sorusuna güreşçiler ve futbolcular evet derken diğer branşlar hayır cevabını vermişlerdir. Bu farklılıklar istatistiki olarak da anlamlılı̆̆ ifade etmektedir $\mathrm{p}<0,00$. Görüldügü gibi spor sakatlıklarıyla ilgi ameliyat olma oranı oldukça düşüktür. $\mathrm{Bu}$ çalışma grubunun amatör ağırlıklı olması bu sonuçları ortaya koymuş olabilir. Elit düzeydeki sporcuların müsabakaları ve yarışma ortamları, şampiyonaların zorlukları değişeceği gibi rekabet ortamı da değişecektir. Daha yoğun ve üst düzeyde yapılan yarışma ortamındaki sporcuların bu oranları da farkl111k gösterebilir.

Şu an tedavi altındamısınız sorusuna tüm branşlarda tedavi gördügünü söyleyen sporcular bulunmaktadır. En yüksek oranda raket sporcularının olduğu görülmektedir. Branşlar arasındaki oranlar istatistiki olarak da farklılığ1 ifade etmektedir $\mathrm{p}<0,00$.

Vücudunuza bir protez takıldı $\mathrm{m}$ sorusuna evet cevabı veren 6 kişi futbolcudur. Diğer branşlarda protez kullanan sporcu bulunmamaktadır. Branşlar arasındaki bu durum istatistiki olarak anlamlı bulunmamıştır $\mathrm{p}<0,05$.

\section{Sonuç ve Öneriler}

Katılımc1ların görme, uyuşma ve his kaybı, nefes alma, göğüs ağrısı ve sıksık kramp girme gibi sağlık sorunları yaşadığı ve bu durumun branşlar arasında farklılıklar gösterdiği görülmüştür. Araştırmaya katılanların \% 49'nun kas kemik ve tendon yaralanmalarına maruz kaldıkları görülmüştür. Ayrıca en yüksek oranlarda, tenisçilerin, görme sorununu, atletizmcilerin nefes alma sorununu, voleybol ve teniscilerin uyuşma ve his kaybı sorununu yaşadıkları görülmüştür. Sık sık kramp sorununu ise yüksek oranlarda badmintoncuların, atletizmcilerin, güreşçilerin ve teniscilerin yaşadığı görülmüştür. Dikkati çeken diğer bir sonuç ise ameliyat önerilen ve ameliyat olan sporcu sayısının da oldukça düşük seviyede olmasıdır.

Spor sakatlıklarının branşlara göre dağılımının bilinmesi, programların planlanmasında, antrenmanların uygulanmasinda gerekli tedbir ve önlemlerin alınmasina, sporcularin bilinçlendirilmesine katkı sağlayacaktır. Bu durumda spor sakatlkklarından dolayı sporcuların antrenman ve müsabakalardan uzak kalmasını engelleyecektir. Ayrıca tedavi masraflarını da azaltarak spor ekonomisine katkıda sağlayabilecektir.

\section{Kaynakça}

Argut, S. K., \& Çelik, D. Genç Sporcularda Spora Bağl1 Yaralanmalara Neden Olan Faktörler. Spor Bilimleri Arastrmalar Dergisi, 3(1), 122-127.

Atay E., Tanır, H., Çetinkaya, E. (2017). Güreşçilerde Sakatlık Bölgelerinin Araştıılması. Adnan Menderes Üniversitesi Sağlk Bilimleri Fakültesi Dergisi, 1(1), 1-4.

Belhan, O., Karakurt, L. (2008). Humerus lateral epikondilit tedavisinde lokal steroid enjeksiyonu ile lateral epikondilit bandajının etkinliğinin karşılaştıılması. Frrat Tip Dergisi, 13(1), 24-27.

Cumps, E., Verhagen, E., Annemans, L., \& Meeusen, R. (2008). Injury rate and socioeconomic costs resulting from sports injuries in Flanders: data derived from sports insurance statistics 2003. British journal of sports medicine, 42(9), 767-772.

Emrah, A., Tanır, H., Çetinkaya, E. (2017). Güreşçilerde Sakatlık Bölgelerinin Araştırılması. Adnan Menderes Üniversitesi Sağllk Bilimleri Fakültesi Dergisi, 1(1), 1-4.

Kilıç, B., Yücel, A. S., Gümüşdă̆, H., Kartal, A., \& Korkmaz, M. (2014). Spor yaralanmaları üst ekstremite yaralanmaları kapsamında omuz yaralanmaları ve tedavi yöntemleri. Uluslararası Hakemli Akademik Spor Sağhle ve Tip Bilimleri Dergisi. Sayl: 12 Cilt: 4.

Kisser, R., \& Bauer, R. (2012). The burden of sports injuries in the European Union. Austrian Road Safety Board.

Kolukısa, Ş., Çolak, H., \& Karakoç, S. (2018). Güreşçilerde Spor Sakatlıklarının Vücut Bölgelerine Göre Dağıllımının Araştırllması. Journal of Current Researches on Social Sciences, 8(1), 245-254. 
Göktepe, M. M., \& Günay, M. (2019). Kadın futbolculara uygulanan proprioseptif egzersiz programının, denge, proprioseptif duyu ve fonksiyonel performans üzerine etkisi. Journal of Human Sciences, 16(4), 1145-1155. doi:10.14687/jhs.v16i4.5863

Kurt, C., Kurt, İ., Çatıkkaş, F. (2006). Sıklet Sporcularında Sağılısız Kilo Verme Yöntemlerinin Kullanım Sıklığ ve Bu Yöntemlere Bağlı Olduğu Düşünülen Yarışma Sırası ve Sonrası Olumsuzluklar. 9. Spor Bilimleri Kongresi Bildiri Özetleri 3-5 Kasım, Muğla.

Öğün, E. S., Ocak, Y. (2018). Frequency and Causes of Injurles In Women Athletes of Basketball B League of Turkey. European Journal of Physical Education and Sport Science.

Ölmez, N., Memiş, A. (2010). Lateral Epikondilit Tedavisinde Kanıta Dayalı Veriler. Turkiye Klinikleri Journal of Medical Sciences, 30(1), 303-311.

Özcan, E., Aydın, R., \& Diniz, F. (1990). Lateral epikondilitte değerlendirme ve tedavi. Acta Orthop Traumatol Turc, 24, 74-6.

Özgür, B. O., Özgür, T., \& Aksoy, M. (2016). Voleybol ve Futbolcularda Spor Sakatllğına Rastlama S1kllğı. İstanbul Üniversitesi Spor Bilimleri Dergisi, 6(3), 50-55.

Palmer-Green, D., \& Elliott, N. (2015). Sports injury and illness epidemiology: great britain olympic team (TeamGB) surveillance during the Sochi 2014 winter olympic games. BrJ Sports Med, 49(1), 25-29.

Rosa, D. P., Borstad, J. D., Ferreira, J. K., \& Camargo, P. R. (2019). The Influence of Glenohumeral Joint Posterior Capsule Tightness and Impingement Symptoms on Shoulder Impairments and Kinematics. Physical therapy.

Sims, S. E., Miller, K., Elfar, J. C., Hammert, W. C. (2014). Non-surgical treatment of lateral epicondylitis: a systematic review of randomized controlled trials. Hand, 9(4), 419-446.

Singh, P., Zhang, M., Pandit, J., \& Mahajan, R. L. (2019, January). Array Jet Impingement Onto High Porosity Thin Metal Foams at Zero Jet-to-Foam Spacing. In ASME 2018 International Mechanical Engineering Congress and Exposition. American Society of Mechanical Engineers Digital Collection.)

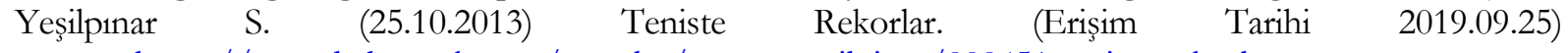
https://www.haberturk.com/yazarlar/sermet-yesilpinar/888451-teniste-rekorlar

Yıldız, M., Demirkan, A. Ç., Yıldırım, Y., Yıldırım, İ., Ocak, Y. (2010) Afyonkarahisar İli Amatör Futbol Takımlarında Oynayan Sporcularda Görülen Sakatlanma Sıklıkları ve Nedenlerinin Araştırılması. Uluslararası Spor Arasttrmalar Dergisi. IJSR 2 (2), 17-36.

Yildız, M. (2018). AN ACUTE BOUT OF SELF-MYOFASCIAL RELEASE INCREASES FLEXIBILITY WITHOUT A CONCOMITANT DEFICIT IN MUSCLE PERFORMANCE IN FOOTBALL PLAYERS. International Journal Of Physiotherapy, 5(3), $92-97$.

Yünceviz, R., Karsan, O., Dane, Ş., Can S. (1997). Serbest ve Greko Romen Güreşçilerinde Spor Sakatlıklarının Vücut Bölgelerine Göre Dağılımı. Gaæi Beden Eğitimi ve Spor Bilimleri Dergisi, 2(4), 1317.

\section{Extended English Summary}

Sports injuries are the names given to any kind of injuries or impairment occurring during the sporting activities (Kiliç, et al.). Sports have important effects on the quality of life. It is especially crucial to get all age groups including young people, children, and elders without making any discrimination adopt the sports habit and to continue them during the whole life. Sports and Physical Activity have also significant influence on the issues of cognitive function, quality of life, and physical health. When adequate precautions are not taken in sports branches, physical performance at the high level that sports require causes sports impairment depending on many internal and external factors (Kisser \& Bauer, 2012). The sports injuries can be categorised as "slight injuries" continuing for 1-7 days, "medium injuries" for 8-21 days, and "serious injuries" for more than 21 days (Emrah et al, 2017).

A lot of sportsmen take more risks, do not take the required protective precautions, and continue the competitions without completing the treatment processes depending on several factors such as winning, gaining an advantage over an opponent, representing his/her country at the best point, having spiritual and financial gain, obtaining social status, and proving to be the best. In this situation, impairment is inevitable.

In this study, it was aimed to identify health problems and types of impairment of the sportsmen carrying out their sports life in different branches and their relationships with sports branches and demographic characteristics. 
Göktepe, M. M., \& Günay, M. (2019). Kadın futbolculara uygulanan proprioseptif egzersiz programının, denge, proprioseptif duyu ve fonksiyonel performans üzerine etkisi. Journal of Human Sciences, 16(4), 1145-1155. doi:10.14687/jhs.v16i4.5863

The participants of the study were 604 individuals including 332 males and 272 females from the braches of Athletics, Tennis, Wrestling, Badminton, Football, Basketball, and Volleyball between the ages of 17-26 and continued their education in the Universities. They took part in the study voluntarily and signed the voluntary participation consent form.

A total of 604 sportsmen participated in this study conducted for revealing the health status and sports injuries especially musculoskeletal injuries of the sportsmen from different sports branches, and the variations among the branches. Of these participants between the ages of 17-26, 74 of them were from Athletics, 47 from tennis, 89 from wrestling, 28 from badminton, 196 from football, 89 from basketball, and 81 from volleyball branch. Also, 332 participants were sportsmen and 272 of them were sportswomen.

As the relationships between the distribution of the participants' health problems and their branches were investigated, it was observed that the sportsmen in the branches of Basketball, Football, and Volleyball had vision impairment less as compared to the ones from the branches of tennis, badminton, athletics, and wrestling, respectively. These results pointed out a statistically significant difference.

As for the question related to having cramp, it was concluded that the badminton players often had it at the highest ratio. Also, wrestlers and athletics and tennis players reported to have cramp at a high ratio following the badminton players. It was seen that football, volleyball, and basketball players had cramp at a lower ratio/ at lower ratios.

These differences between the branches were also statistically significant $p<0,01$. The cramps observed more in individual sportsmen can be explained with that the physical overloading has been performed in an intensive way and at maximal severities in these branches and especially also with that the competition grounds of tennis and badminton have been hard and durations of these competitions have been long. Additionally, that the wrestlers have experienced a high ratio of cramp problems can be explained with the fact that, among the combat sports, wrestling is a branch performed at a high difficulty level and with an opponent contact.

In the answers given to the questions asked to sportsmen about the appearance of numbness and sensation loss, it was stated that the volleyball and tennis players suffered from sensation loss at the highest level, respectively. It was observed that the ratios of appearance of numbness and sensation loss in other branches were quite low in the other branches. These differences between the branches were also statistically significant $\mathrm{p}<0,00$. This case and the differences can be explained with the specific structures of the branches. It has been seen that especially tennis and volleyball players suffer from "lateral epicondylitis" and "Shoulder Impingement Syndrome" accepted as occupational impairments specific to branches.

One of the important findings attracting attention in the results of the study was that $49 \%$ of the participants stated that they had suffered from muscle, bone, and tendon injuries. In other words, half of the participants had suffered from sports injuries.

While $8,3 \%$ of the participants said "yes" to the question whether surgery had been offered due to sports injuries, $3,1 \%$ of them stated that "I had surgery due to sports injuries". There were six people said "yes" to the question whether any prosthesis had been fitted in your body and percentage equivalent of this number was $1 \%$. As seen, the ratio of the cases requiring surgery following the injuries and the number of sportsmen having surgery were quite low. This situation has inferred that the injuries have been generally treated by not requiring surgery.

Six people were the footballers who said "yes" to the question whether any prosthesis had been fitted in your body. There were not any sportsmen using prosthesis in the other branches. This case among the branches was not found statistically significant $\mathrm{p}<0,05$.

As a result, it was observed that the participants suffered from health problems including vision impairment, numbness and sensation loss, breathing disorders, chest pain, and frequent cramps, and this showed differences among the branches. It was detected that $49 \%$ of the participants exposed to muscle, bone, and tendon injuries. Moreover, it was seen that, at the highest ratios, tennis players suffered from vision problem, athletics players suffered from breathing problem, and volleyball and tennis players suffered from numbness and sensation loss problems. Furthermore, badminton players, athletics players, wrestlers, and tennis players suffered from the frequent cramp problem at high ratios. Another important result attracting attention was that the number of the sportsmen who were offered a surgery or had a surgery was quite low. 